\title{
Chapter 6 \\ Mediation and Conciliation in Collective Labor Conflicts in France
}

\author{
Alan Jenkins, Christian Thuderoz and Aurélien Colson
}

\section{The Case}

At the Pont de Chaume Clinic in Toulouse, towards the end of 2015, 130 employees went on strike for 51 days for better working conditions and better pay. Two mediators intervened in order to revive negotiations: Pierre G. from the local labor administration and Michel S. an independent lawyer and mediator. In an interview for the local newspaper Michel S. stated- "We need to consider much more the possibility of associating independent mediators like myself with local representatives of the labor administration like Pierre, who also plays a mediation role (through his conciliation activities). That would give us different perspectives which would be complementary and mutually enriching; in addition we could profit from the rich networks and resources of the state".

Here we find certain typical features of the French recourse to mediation: it is usually brought in to tackle long declared conflicts between parties whose relationship is often oppositional and confrontational, with a history of poor negotiation and little compromise. The local labor administration (often work inspectors) is usually involved in some capacity, but a fourth actor is emerging, apart from the state, unions and management - the independent mediator, a member of a promising but as yet unstructured professional community.

\footnotetext{
A. Jenkins $(\varangle) \cdot C$. Thuderoz $\cdot$ A. Colson IRENE and ESSEC Business School, Pontoise, France e-mail: b00000265@essec.edu 


\subsection{Characteristics of the System}

\section{Collective conflict: definition and meaning in France}

Our study concerns both (what are called in French) "conflits collectifs de travail", such as strikes, with their repertoire of symbols and ritual actions, and "conflits collectifs au travail" which can concern a whole range of management-employee tensions and hostilities in the workplace. Study of the first type of conflict has traditionally been linked to that of the unions and the "workers movement" of course. Study of the second "horizontal" type of conflict, where neither top management nor unions may be involved, is relatively recent in France and requires a different conceptual tool box to the first- there is a limited range of material on these subjects in French, as Sainsaulieu (2017) notes.

When questions of honour, status, discrimination or recognition (for example) underlie organizational conflicts, or become involved in them, then their resolution will often be slow and probably painful for the parties. Some form of mediation may well be essential to the process. In France "classical" union-management conflicts are usually handled, if a third party is needed, negotiation failing, by a local labor administration and by local "Inspecteurs du travail" (work inspectors): this is called a process of conciliation (see below). Our study concerns both types of conflict and their associated processes or regulation and resolution. But whether they are "vertical" or "horizontal", the same elements are involved: a space of conflict, where each actor chooses their enemy and rejects them as a "partner"; a dynamic of conflict, which can become chronic, in which the parties become victims of what they have initiated; facilitating conditions which maintain the dynamic by preventing pragmatic compromise, and finally positive conflict functions, which actually help the emergence of renewed relationships from within discord.

\section{Collective conflicts in France: fewer in number, but more diverse in form}

In recent years collective conflicts have both fallen in number and been transformed in nature. The decline in recourse to the strike is spectacular: in 1976 more than 4 million days of work were lost to them, in 1986 500,000, in 2006 110,000 and in 2016 only $60,000 .{ }^{1}$ In 2015 only $0.2 \%$ of French firms of fewer than 50 employees experienced a strike; a little more than $3 \%$ in those of 200 employees, but $30 \%$ of companies of more than 500 employees. These differences can be correlated with union presence- $88 \%$ of firms experiencing at least one strike in 2015 had at least one union representative, and $92 \%$ of those same firms were undertaking collective bargaining. There is nothing surprising about that-union presence is greater in bigger firms, firms where collective bargaining is most dynamic. ${ }^{2}$

\footnotetext{
${ }^{1}$ See Dares-résultats, No. 65, October 2017: http://dares.travail-emploi.gouv.fr/IMG/pdf/2017-065. pdf.

${ }^{2}$ It is worth remembering that while only $11 \%$ of employees in France are union members $50 \%$ vote in union elections in their respective organizations (see Colson, Elgoibar, \& Marchi, 2015; Dares, 2013).
} 
The "repertoire of collective action" (Tilly, 1986) has become enriched by new forms of protest that complement the older ones, still used periodically (and often ritualistically). So many forms of conflict action can co-exist: short strikes at "strategic" junctures for the firm, individual stoppages, absenteeism, refusal to work overtime, slow down and work-to-rule, participation in national and local demonstrations, signature of petitions, and use of social media and broader critiques of management attitudes and behavior in blogs and other media.

However on the management side much of this seems now to be better anticipated and handled. Going from "early warning" or "alert" systems (used much in the French transport sector), to better use of formal strike warnings ("préavis de grève") in the public sector, to better consultation of works councils and other organisms of representation. Also, there is a tendency to more informal meetings between management and employee representatives to defuse tension and stress, to creating a "Joint employer-union regional committee" in order to help dialogue in small and medium-sized firms, or a "Local agency supporting social dialogue" in each French county. These systems were all implemented during 2017.

\section{The French tradition of collective bargaining and negotiation}

Anticipating somewhat, we can say that there is no structured mediation "system", as such, in France. There is certainly an industrial relations (IR) system of some complexity and inertia in the country and, we would argue, it is the weight of this inertia that in part conditions approaches to mediation, making mediation marginal. In this we confirm the conclusions of other researchers like Teissier (2014). This marginality can be partly understood by examining the norms defining the traditional methods of collective conflict management in France-specifically those impacting on patterns of negotiation. As Moore (1996) and others have argued, mediation is essentially "an extension or elaboration of the negotiation process".

Despite a seemingly voluminous and intensive negotiation activity at the level of both sector (the "branche") and organization, reflected in the available annual statistics $^{3}$ the multiple efforts of successive governments to make collective negotiations qualitatively richer, usually through both exhortation and law, have had limited success. In addition, extensive innovation has not come from the actual negotiation experiences of employers and unions "on the ground". A somewhat inert system, inflexible and resistant to change, has been the result. This is one of the central points made by Combrexelle (2015) in his report to the Prime Minister.

In the French tradition negotiation at the sector level has always played a crucial intermediate role in a pyramid of regulation which features, at the apex, a voluminous Labor Code of nearly 3000 pages and, at the bottom, enterprise or organizational agreements and finally, the work contract of the employee. Sector level negotiations have been crucial in the fixing of minima for employees in the associated firms, concerning issues such as wages, training, pensions and retirement provisions. Crucially, a principle of prioritization has governed the relations between these levels (e.g.: the

\footnotetext{
${ }^{3}$ Direction générale du travail, DGT/DARES (2013 and 2016).
} 
requirements of an agreement at organizational level can legally override those at sector level only if they are more favorable for the employee).

It is worth mentioning that $95 \%$ of French employees are covered by such agreements but that this high number is related to the fact that when an agreement is reached it will apply to all employees in the sector and not just those who are members of the main union signing the accord. A second important point is the sheer complexity and diversity of the architecture and activity of sectors in France, one largely considered in need of reform. The country includes 700 sectors and almost one third of these have not ratified a collective agreement in the last ten years.

The role of the state and the law: inertial?

Without enumerating in detail the successive legal changes enacted since 1982, what have they contributed, overall, to the French IR system and French collective negotiations? Essentially, the greater autonomy accorded to company agreements mentioned earlier has been complemented by three shifts in the law: firstly, more flexibility in the French Labor Code concerning the negotiation of working time; secondly, in the area of employment, the reinforcement of the negotiation of manpower planning, Sunday working, sexual discrimination, contracts between generations, etc.; and thirdly, reorganizing and rationalizing the different obligations of the social partners to negotiate at the organizational level.

The rising density of the Labor Code has generated a kind of "stacking up" of obligations to negotiate, with the perverse result that not only are simplicity and clarity lost, but also the available room for relatively free dialogue and flexible negotiation is actually reduced. Dialogue is saturated by obligations such that the actors involved in negotiation do not appropriate for themselves, openly and voluntarily, the mechanisms and opportunities the state and law are trying to make available. Negotiating can become seen as a purely formal administrative necessity, one among many, that takes employers and employees away from the essential—getting the day-to-day work done in the organization. Arguably this saturation has had the long term effect of framing expectations, regarding negotiation itself as an activity, in a particular way. As Combrexelle (2015) puts it:

One of the main difficulties lies in the way in which the actors get involved, and not just the unions but companies as well, interpret and undertake collective negotiations. That is to say, how far they see such negotiation as useful, equitable and efficient and how much they use the resources that the law offers them. (p. 47, our emphasis).

\section{The "culture of negotiation" and patterns of interaction}

In 2018 the verdict of many commentators on patterns of negotiation in the French industrial relations system is harsh, highlighting three problems which seem to have remained constant (and perhaps to have deepened) across the decades.

Firstly, there is the issue of how much the French system-in its fundamental nature and despite different state reforms - has actually encouraged and facilitated negotiation in companies in the different strata of the economy. Combrexelle's view is particularly strong: in the largest firms on the stock exchange (the CAC 40), collective negotiations have become marginal in importance to top deciders, and largely 
the responsibility of specialized legal counsel and human resources personnel whose influence on, and involvement in, strategy and key decisions has never been substantial. Secondly, in small to medium-sized firms there is a triple problem-negotiation processes seem too long for effective decision-making, the law surrounding negotiation is too dense and complex, and thirdly, agreements signed are unstable in law and open to litigation. As for very small firms, their experience of the previous problems is even worse because of the lack of any legitimate employee representation and negotiation beyond the direct one-to-one relations between managers and employees that exist in any small concern.

The second issue concerns the mutual perceptions of employers and unions of each other's skills (and thus of their respective pertinence and utility as a negotiation partner) and the third, the crucial issue of mutual trust. We can argue that only when skill and trust perceptions of the principal actors improve will dialogue (and by implication negotiation practices) become more constructive (Euwema et al., 2015). Evidence regarding France in this work suggests that HR and line managers perceive employee and union representatives as relatively poor in the types of skills that they would wish to see in a viable and credible negotiating partner, one able to bring constructive and innovative problem-solving capabilities to the table and negotiate agreements that help the firm compete as well as benefit its employees (Colson, Elgoibar, \& Marchi, 2015). Employee representatives are also seen as overly partisan and ideological in perspective, leading to predictable and rigid negotiating positions that exclude the kind of flexibility, openness and perceived integrity needed to build a vital minimum of trust at the negotiating table, a pre-condition for cooperation and joint value creation.

On the other side, unions and their representatives often accuse managers of authoritarian and high-handed practices, of being unwilling to share company and strategic information, of hypocrisy and deception, along with having "strategic incompetence" in areas vital for the survival of the firm and for the guaranteeing of stable employment for workers.

The result is negotiation processes and practices which are weak when they could be strong, inertial instead of dynamic. Negotiation in the IR system in France is, in this view, often seen as a rather empty, formal and ritualistic obligation.

\subsection{Mediation in France: From the Legal Framework to the Emergence of a Mediation Market}

\section{The legal framework concerning the role of third parties in labor disputes}

The French Labor Code refers to three legal mechanisms (in Laws L.2522-1, L.25231 and L.2524-1): conciliation, mediation and arbitration (Clark, Contrepois, \& Jefferys, 2012).

- The conciliation procedure can be freely chosen by the parties in conflict. It is initiated and led by the Work inspector in whose jurisdiction the company operates. 
It can also be proposed by a joint commission (sectorial, regional or national) composed of representatives of employers, employees, and the state, in equal numbers. The mediation procedure can be initiated either by the Chair of the conciliation commission, who encourages the parties to appoint a mediator, or (as is often the case) by the administrative authorities (at national, regional or county level, as the situation demands) following a written request from the parties, stating their reasons.

- An arbitrator is chosen by the parties involved in the dispute, or under the terms agreed by the parties. Arbitral awards should be explained and should not be subject to any other appeal except one before the Supreme Court of Arbitration.

Conciliation was first enshrined in law on the 27th December 1892; it established the opportunity for opposed parties to refer to a local conciliating magistrate within three days. The goal was to "anticipate or attenuate conflicts between capital and labor and, above all, to avoid and shorten strikes". However, the procedure was in fact little used.

The frequent parliamentary debates surrounding these laws come back time and again to the fact that, over a very long period (1892-1982), conciliation commissions were rarely used (despite a legal obligation) and few conflicts went into mediation. What are the reasons for that? Firstly, some conflicting parties seem to have been afraid of the implications of resolution in the presence of a third party (magistrate or prefect); and employers were concerned about making concessions to strikers during conciliation that they had resolutely rejected during the entire strike period. Further, while conciliation/mediation might have been seen as appropriate for resolving conflicts of interest, conflicts of rights (as in the interpretation of conventional, legal or normative clauses) were seen as ill-suited to such intervention. The relevant parliamentary debates reveal concern that mediation/conciliation rulings would become jurisprudence and thus compete with the legal interpretations and judgements of tribunals. Added to this was the fear that mediators would become the real architects of collective agreements at the level of sector or firm, thus diminishing the "private co-legislator" powers of the parties in conflict.

\section{A growing mediation market}

Many indicators of the rise in use of mediation in the workplace (since around 1990) are available. Firstly, the growing number of practitioners, of mediation networks and associations, and of training programs (public/university or private); secondly, the development of debate and controversy in this mediation milieu often dealing with issues of professional competence and qualification; thirdly, the gradual structuring of these mediator networks, on the slow path to institutionalization and professionalization.

This rise has been pushed by three intertwined ideological, institutional and socio-economic vectors: firstly a humanist ethos, promoting an ethic of empathy, non-violence and social harmony, of cooperation rather than competition (the "empowerment" of individuals and groups is a key theme here (Faget, 2010)). The second factor is an institutional drive, articulated by the state, judicial and local authorities, 
who have seen in mediation a practical solution to the increasing costs and delays of litigation and the habitual recourse to tribunals for the management of conflicts (Vert, 2014). Finally there is a private service/market response from consultancy and mediation professionals, making themselves available to handle, for a price, the complexities of inter-group tension in pluralistic societies. This third phenomenon will be addressed now.

Why should we speak of a "market" for mediation in the area of collective conflict regulation in France? Because a supply and demand for mediation services, and their "sale and consumption", clearly exists in this country and this space for exchange needs to be understood using the usual socio-economic tools. This is important given the high level of rhetoric and ideology surrounding the promotion and use of mediation in France.

Three shifts lay behind the expansion of mediation in the workplace and in organizations: a search for alternatives to litigation, a need for professionalization and a quest for appropriate methodology. Back in the 1990s, the first mediators in France were essentially legal personnel, lawyers above all, just as the first theoreticians of the practice were university law academics with both an interdisciplinary orientation and a strong motivation to give greater voice and power to the parties involved in conflicts. Hence the promotion of a certain "justice douce", to use the term of JeanPierre Bonafé-Schmitt (1992), one of the pioneers of mediation in France, giving priority not to abstract rules and norms, but to a negotiated resolution of conflict starting from a recognition of the needs of the parties, and to a rebuilding of their relationship on a solid basis. This was understood as not just "alternative dispute resolution" (ADR), avoiding the courts, but more ambitiously as social reconstruction, changing socialization processes and the "spaces" of social cooperation and collaboration.

Conflict in the workplace was one of the later domains to be impacted by the trend, as Le Flanchec and Rojot note in 2009: "Despite the existence of certain procedures allowing the use of mediation and arbitration for work conflicts, not only is its use in France weak judicially, but it is poorly developed in companies". As these authors document, some of the first processes for "internal mediation" were experimented with in the SFR-Cégétel Group starting in 2002, the fruit of a company collective agreement. Other firms and administrations would follow. Today most of the big public companies in France (La Poste, EDF, SNCF, etc.) have an internal mediator and an ad hoc mediation service.

\section{A market which is segmented and scattered}

The mediation market is split between sectors and sub-sectors of activity with skills built in one area of specialization often difficult to transmit to another. When the actors and conceptual frameworks involved in conflicts change then mediation practices can be difficult to transfer in any meaningful and effective manner. The scattered nature of the market (similar to that for "organizational consultancy" in areas like change management) is also evident: in France there is a myriad of mediation firms, networks and structures, often built around founding figures or a favored mediation training method and "philosophy". Their size and approach are highly variable 
and differentiated, and interaction between them has no clear discernible pattern, nationally. However, in one or two geographical areas (notably the cities of Lyon and Grenoble) some cooperation and mutual learning across firms and networks has developed, although it seems fragile and uncertain.

In fact there seem to be two "sub-markets" here-firstly a market with a supply of independent producers usually working in small networks and structures ${ }^{4}$ (grouping a few mediators but all concerned to conserve their autonomy) and secondly a market of associations or small organizations, many run according to the French governance law of "Loi 1901". Some structures are hybrids, like the ANM (Association nationale des médiateurs) which sees itself as "a place for exchanges, training and professional development" providing its members with professional and technical support but also as a "platform able to supply to any given client a mediator with recognized skills and professional independence".

Conflicts between individuals at work, between groups there, and between management, labor and their representatives are all situations for which mediator help may be sought, but the dominant role of the third party in each of these will be different.

For the first type of conflict the mediator will usually be a member of an organizational hierarchy, such as a department head or an employee representative, charged with managing the dispute because of their status, experience and personal qualities. They mediate for many different reasons, from their belief in a role of independent problem solver, to their hope of benefits in some form, for themselves (or their group) or the organization as a whole.

The second type of conflict, involving a number of individuals, usually entails (after internal failure) a top manager or HR director calling in an external private mediator, found through a social network or recommended by a professional association they know. The choice of this third party depends on the proposed methodology, the personal aura, the reputation of the network s/he belongs to, etc. That market is expanding, even though techniques of collective mediation are under-developed-all of our interviewees stressed that a collective mediation clearly cannot be the sum of individual ones and that, faced with groups and group emotionality, special methods are required (such as co-mediation).

The resolution of the final type of conflict (of which the strike is the "archetype") is in France often dominated by the conciliation work of the work inspector covering the organization and its sector. Much of this social regulation thus escapes the domain of private mediators. There are two reasons here. One is the institutional role of the Inspecteurs, enshrined in labor law; and the other is the highly significant fact that this intervention/conciliation is free to the company and without formal time limit, unless another actor with appropriate formal authority (such as a local Prefet) intervenes to require an external mediator to help resolve the dispute.

\footnotetext{
${ }^{4}$ For example the RME (Réseau des médiateurs d'entreprise) sees itself as a "network for analysis and development of practices for the promotion of mediation in companies, as well as for the development of its members" https://www.mediateurs.fr/.
} 


\subsection{Three Types of Mediator Role}

\section{The "occasional mediators": artisans of day-to-day conflict management}

This type of mediator is largely unknown, but actually an important figure in maintaining everyday cooperation and calm in the firm. Whether s/he is a union representative, a department head or a respected senior employee, such individuals play a mediating role. Their action is part and parcel of the fabric of social relationships in the organization, unlike the "classical" mediator whose effectiveness depends on neutrality and distance from them. The former, thanks to assets like status, charisma and experience can promote reconciliation and bring to light convergences beneath differences of opinion.

\section{The private sector mediators/consultants}

Here we can distinguish three types of private sector mediations, if we look at them from the point of view of the client and his/her demands.

- "Transaction mediation", called in French texts "médiation conventionnelle", where the parties to a conflict turn to a freely chosen third party to obtain a mutually acceptable agreement. This will be an expert, academic or consultant whose task is to help the parties negotiate together and end litigation.

- "Resolution mediation", called in France "médiation judiciaire" (or "médiation contrainte" by many of our interviewees). This is demanded by the state, locally or nationally, and the goal here is not to "accompany" the parties but to resolve the conflict "hic et nunc", without further legal proceedings.

- "Regulation mediation", deployed over the long term, a kind of mix between collective coaching and change management. The goal here is to maintain the momentum of an organizational change process.

Mediator-conciliators: work inspectors between control and "wait-and-see" conciliation

The intervention of work inspectors in collective conflicts in France is paradoxical-it is both widespread and negligible in overall impact. It is widespread because the inspectors have a quite intimate knowledge of the firms under their jurisdiction ("When you practice mediation in a company the process is broadly the same as for other settings; however, I think it is necessary to have quite detailed knowledge of the organization itself", Interview) and so certain conflicts are managed in the offices of the work inspection.

The report of the DGT on the activities of inspectors in $2015^{5}$ suggests that their conciliation role is important but not really fully reflected in the statistics compiled. Such acts of conciliation are said to be "numerous, effective and very beneficial for

\footnotetext{
${ }^{5}$ L'inspection du travail en France en 2015, DGT, Ministère du Travail. Paris: La Documentation française, 2016.
} 
the functioning of the companies concerned". Conciliation is "ad hoc and unplanned very often, case-by-case work in which inspectors adapt to local conditions" (p. 146).

Yet at the same time we can say that conciliation is rather negligible when counted within the other responsibilities of the inspectors. The DGT report admits that each year since 2010 only $1 \%$ of the time of work inspectors is devoted to that activity while $51 \%$ is devoted to company visits and $43 \%$ to documentary analysis. In 2015900 conciliations were carried out by Inspectors, but that represents only 3 interventions per working day during a given year, for the whole of France.

Work inspectors seem to intervene, usually, only after being solicited by the parties, this making impossible important preparatory work in conflict prevention. The DGT report also adds a sociologically interesting point-when a collective conflict is threatening, or actually breaks out, inspectors usually allow the power struggle between the actors to unfold. In the case of intense or publicly visible conflicts they may operate as a small group. They are said to intervene rarely of their own initiative but wait to be called upon to help with negotiation or to find a solution. Discretion is one of their major obligations: they operate "behind the scenes".

Overall, the DGT report sends a contradictory message about the Inspectors' work of conciliation - on the one hand it is called "important and substantial" while being unknown to the public, but on the other hand no examples or analyses at all of such work are provided in the document.

\subsection{Debate in the French Mediation Community}

Building on the data from our interviews, we must raise the issue of rift and disagreement, of dispute, within the French community of mediators. These are at times controversies, debates whose arguments and counter-arguments can be traced, but at others simple differences, either of point of view regarding method and/or practice. Identifying and analyzing these disputes is useful because, beyond the calm, neutral and conventional mediator discourse of self-promotion one finds in France, they reveal in part the state and structure of the field of mediation. This is also, of course, a struggle over the legitimacy of mediation in a specific institutional context which is already occupied by other actors with claims to do mediation or conciliation (organizational and industrial relations consultants, work inspectors, etc.). As one interviewed mediator said: "Many combine and confuse coaching and mediation, the roles of coach and of mediator. That is a mistake... In addition, beware the confusion between the mediator and the organizational consultant!".

The French mediator community's disputes feature three major tensions and debates. Firstly, differences regarding central goals structure the mediator community very significantly. While mediators are generally in agreement on a certain minimum definition of what mediation actually is, that is not the case when further detail and deeper questions are brought into the picture (ROM, Rassemblement des organisatuions de la médiation, 2009). 
A reading of the homepages of the main mediation web sites in France reveals a broad spectrum of views about the social functions of mediation; if for some, mediation is confined to "easing tensions in the workplace through joint problemsolving accepted by the parties" (website of the CNPM), in others much more ambitious goals are highlighted (e.g.: the rebuilding of social relations and the pursuit of projects shared between the parties). The French Ministry for Territorial Integration defines mediation as a process of "recreation and rebuilding of the social fabric", and an author like Faget (2010) sees mediation practices as "new ways of giving life to democracy, discreetly and silently".

On the other hand, the well-established network RME "Réseau des médiateurs d'entreprise" insists on the operational value of mediation in an organizationforeseeing psychological and health risks, raising collective performance, reducing absenteeism and the loss of skills, managing both individual and collective conflicts and developing learning capacity for future conflict regulation.

Raise collective performance or build a harmonious community? The difference between the two is considerable, expressing two different views of mediation's central goals: mediation as tool/technique or mediation as shared project. The second view is widely held in France, with many books and articles exalting an almost metaphysical goal for the practice.

A second important controversy within the mediation community concerns the scope and scale of mediation interventions themselves. Here what we might call the "depth" of intervention is an issue. It stems from a practical difficulty: how can we get the disputing parties to a solid agreement without examining the deeper organizational, motivational and socio-psychological causes of their conflict? Should the mediator simply try to repair a broken relationship or go further and build a better form of coordination relation for the future? Again, can and should the mediator be a coach or organizational consultant such that his/her mission goes beyond getting agreement between two parties and forging significant organizational change?

After all, many collective conflicts are those which the given organization, with its specific resources, has failed to resolve and a third party can-with an appropriate diagnosis and with available time-bring to light what is systemic (and perhaps chronic) about them. In such a complex situation of change, simply gathering the disputing parties around a table hardly allows the mediator to understand properly and in depth what is systemic to their conflict, as Kressel (2007) notes in his discussion of the importance of what he calls "strategic mediation". Should the mediator then undertake an in-depth sociological study, or simply confront the stories of the parties, knowing that this latter reduces the likelihood of bringing valuable new knowledge (of themselves, the organization, etc.) to them?

Opinions on this within the French mediator community vary of course, between flat refusal and open acceptance of joint regulation and assistance. The refusals are usually founded on the idea of strict respect of a mediation mission, whose scope is agreed and formalized with the client, or on a reading of conflict as an asymmetry of interests which can be overcome through empowering the parties. At the other end of the scale, some mediators offer mediation as but one element of a broader set which 
often looks like organizational consultancy and may include coaching techniques (the RME in France calls this "multi-element engineering").

As one of our interviewees insisted, "Mediation must be seen in a general sense, with a diversity of meanings. There is "pure" mediation, but there is also assisted negotiation, conciliation, coaching and arbitration, etc. These tools need to be carefully combined. Conciliation is favored by HR Directors but the unions prefer mediation, so we need a range of tools. We must not remain locked into mediation as the only technique. In addition, we need to be ready to go further in helping our clients deal with change, post-mediation, if they need that help".

Another debate across the mediator community concerns the economics of mediation production. Should mediation be delivered according to a standardized method, reducing the risks of subjectivity and distortion, and helping experiential learning, or on the contrary should "made for measure" and customization always prevail?

Some of our mediators say they use both of these contrasting approaches but, inevitably, this opens up the issue of the quality assurance of mediation delivery. One French network, the EPMN, has tried to differentiate itself from others by a sharp criticism of their methodological approach; for the EPMN, truly professional mediation is far from the "therapies" that others propose to clients. The former is structured and rational whereas the latter is moralistic, pseudo-psychological and quasi-philosophical in basis. In contrast, other mediators interviewed insist on the need for flexibility in the use of different methods; "to know clearly where you are going, but not always requiring fixed steps or phases to get there”.

\subsection{Conclusion: The Role of Mediation in Rendering French Conflict Resolution More Effective}

To conclude, we need to consider the possibilities of the development of mediation in three distinct conflict phases.

The Pre-conflict phase includes those key moments when differences of points of view can become disputes, which can then mutate into conflict. When the analyst reviews the chronology of a collective conflict s/he is often intrigued by the existence of many "warning signs" that all the actors involved failed to see or to understand. To deal with this important problem there is significant "capacity building" to be done, helping all the parties to better see those danger signs and thus reduce the risk of conflict breaking out and becoming destructive. Here one thinks immediately of generalizing the kind of industrial relations early warning system that has existed in the Parisian metro organization (the RATP) since 2001. Such a system ties the parties (by a contractual obligation) to regular joint examination of "danger signals" in the social climates of different departments. Also stipulated is the right of the parties to call on a local joint commission, or on work inspectors, to set up a preventative mediation. Another element is the provision to the social partners of a detailed guide to "trouble shooting" disputes, designed to help them improve dialogue and to better 
compare their points of view and underlying assumptions (similar in spirit to those developed by ACAS/TUC (2016) in the UK).

The conflict itself, if sometimes necessary, should not drag on for too long; that is a dynamic which "creates victims" and new complex psychological conditions. So, after a short period (of perhaps one week) recourse to the labor administration could be initiated, either by the parties themselves or by work inspectors. Work inspectors would not wait to be called, but react more quickly and be pro-active in proposing conciliation or mediation. This would require the in-depth training of work inspectors in specialized mediation methods, something which is at the moment sorely lacking.

One could also imagine the French labor code authorizing the parties during a conflict to appeal freely to a mediator of their own choice, and this at any time and independently of the local labor administration, so long as the mediator concerned is recognized by the state as fully qualified (and thus listed as such by the local Prefecture) (Durand, 1999). In order to reduce the likelihood of refusal from one or other of the parties, pairs of mediators (with different orientations - an ex-HR Director along with a seasoned union representative, for example) could be proposed. ${ }^{6}$

The techniques used by mediators of collective conflicts could also be improved - through the provision of detailed written guidelines, handbooks and texts on methodology, for example - in order to raise aggregate skill levels (Colson, Lempereur, \& Salzer, 2008). Local and regional fora of exchange on cases and best practices, and examination of the statistics on conflict collated by labor administrations, could also be organized.

The effectiveness of such mediation would also probably be improved if mediators themselves went beyond "dialogue facilitation" to embrace the more technical role of providing detailed scenarios of resolution. While re-establishing constructive communication is important, the crucial role of helping with forms of joint regulation and cooperation in day-to-day decision-making should not be neglected. ${ }^{7}$

Finally, the post-conflict phase requires, in addition to the changes mentioned previously, a system that supports and maintains cooperative social dialogue between the social partners. This could be part of a clinical follow-up approach to the parties in conflict undertaken jointly by work inspectors and the private sector mediators involved. If this lasted an appropriate length of time it could help the parties to both heal their wounds and to reconstruct their relationship and rebuild trust (when appropriate) with the active help of third-party expertise.

What this means overall is that in our perspective, for collective conflicts in the French workplace, it will be important to think in terms of broad missions of mediation where different professionals (coaches, organizational consultants, mediators, etc.) might help the parties in different ways and at different points in their conflict trajectories. That in turn, clearly, needs to be part of a better, broader process of

\footnotetext{
${ }^{6}$ The system has been used with success in both Martinique and Guadelope since 2012.

${ }^{7}$ The ILO definition is as follows: "Mediation can be considered as a special method for conflict resolution in which (even if the conflict continues to be 'governed' by an agreement between the parties) a third party who intervenes is more deeply involved than in conciliation and can have the authority (and even the obligation) to make formal proposals for the resolution of the conflict". (Our emphasis) http://www.ilo.org/legacy/french/dialogue/ifpdial/llg/noframes/ch4.htm.
} 
socialization and acculturation of employers and employees - in problem-solving dialogue, in negotiation and in mediation processes. France is at the moment, in its industrial relations reforms, moving slowly in this direction.

\section{References}

ACAS/TUC. (2016). Mediation: A guide for trade union representatives. London: ACAS.

Bonafé-Schmitt, J.-P. (1992). La médiation: une justice douce. Paris: Syros.

Clark, N., Contrepois, S., \& Jefferys, S. (2012). Collective and individual alternative dispute resolution in France and Britain. The International Journal of Human Resource Management, 23(3), 550-566.

Colson, A., Lempereur, A., \& Salzer, J. (2008). Méthode de médiation. Paris: Dunod.

Colson, A. Elgoibar, P., \& Marchi, F. (2015). "Employee representatives in France: Employers perceptions and expectations towards improved industrial relations". In Euwema et al (Eds), 2015.

Combrexelle, J. D. (2015). La négociation collective, le travail et l'emploi: Rapport au Premier Ministre. Paris: France Stratégie.

Direction générale du travail, DGT/DARES. (2013 \& 2016). Bilan annuel de la négociation collective, 2012 et 2015. Paris: La Documentation française.

Durand, T. (1999). "Histoire d'une médiation dans un conflit social: quelques implications pour le management stratégique". In Ingham, M. \& Koenig, G. (Eds.), Perspectives en management stratégique. Management.

Euwema, M., et al. (Eds.). (2015). Promoting Social Dialogue in European Organizations. Heidelberg: Springer Open.

Faget, J. (2010). Médiations: les ateliers silencieux de la démocratie. Paris: Erès.

Inspection du travail. (2014, 2016). L'Inspection du travail en France en 2013 et 2015. Paris: DGT.

Moore, C. W. (1996). The mediation process. San Francisco: Jossey Bass.

ROM, Rassemblement des organisations de la médiation. (2009). Code national de déontologie des médiateurs, Press Book. Paris: ROM.

Sainsaulieu, Y. (2017). Conflits et résistances au travail. Paris: Presses de Sciences Po.

Teissier C. (2014). La place des représentants élus du personnel, des pratiques référendaires et des formes de médiation dans la négociation collective d'entreprise. Paris: Commissariat général à la stratégie et à la prospective (ASTREES/CGSP).

Tilly, C. (1986). The Contentious French. Harvard: Harvard University Press.

Vert, F. (2014). Médiation: mode d'emploi. La Gazette du palais. 14-15 November.

Open Access This chapter is licensed under the terms of the Creative Commons Attribution 4.0 International License (http://creativecommons.org/licenses/by/4.0/), which permits use, sharing, adaptation, distribution and reproduction in any medium or format, as long as you give appropriate credit to the original author(s) and the source, provide a link to the Creative Commons license and indicate if changes were made.

The images or other third party material in this chapter are included in the chapter's Creative Commons license, unless indicated otherwise in a credit line to the material. If material is not included in the chapter's Creative Commons license and your intended use is not permitted by statutory regulation or exceeds the permitted use, you will need to obtain permission directly from the copyright holder.

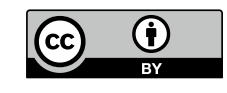

